\title{
Very high rates of vitamin $D$ insufficiency in women of child-bearing age living in Beijing and Hong Kong
}

\author{
Jean Woo ${ }^{1}$, Christopher W. K. Lam ${ }^{1}$, Jason Leung ${ }^{1}$, Winny Y. Lau ${ }^{1}$, Edith Lau ${ }^{2}$, Xu Ling ${ }^{3}$, Xiaoping Xing ${ }^{3}$, \\ Xi He Zhao ${ }^{3}$, C. Murray Skeaff ${ }^{4}$, Catherine J. Bacon ${ }^{5}$, Jennifer E. P. Rockell ${ }^{4}$, Aaron Lambert ${ }^{6}$, \\ Susan J. Whiting ${ }^{7}$ and Timothy J. Green ${ }^{4 *}$ \\ ${ }^{1}$ Faculty of Medicine, The Chinese University of Hong Kong, Shatin, New Territories, Hong Kong \\ ${ }^{2}$ Hong Kong Orthopaedic and Osteoporosis Center for Treatment and Research, Unit 1301, Hing Wai Building, 36 Queen's Road \\ Central, Hong Kong \\ ${ }^{3}$ Peking Union Medical College Hospital, Beijing, China \\ ${ }^{4}$ Department of Human Nutrition, University of Otago, PO Box 56, Dunedin, New Zealand \\ ${ }^{5}$ Department of Medicine, The University of Auckland, Auckland, New Zealand \\ ${ }^{6}$ Fonterra Brands Ltd, Auckland, New Zealand \\ ${ }^{7}$ College of Pharmacy and Nutrition, University of Saskatchewan, Saskatoon, Saskatchewan, Canada
}

(Received 25 June 2007 - Revised 7 September 2007 - Accepted 10 September 2007 - First published online 26 October 2007)

\begin{abstract}
We aimed to describe the vitamin D status of young women living in two Chinese cities in the spring - Beijing in the north (latitude $39^{\circ}$ north) and Hong Kong (latitude $22^{\circ}$ north) in the south. We also examined the relationship between serum 25 -hydroxyvitamin D and parathyroid hormone (PTH) concentrations to determine a threshold for serum 25-hydroxyvitamin D above which there is no further suppression of PTH. Finally, we examined whether dietary $\mathrm{Ca}$ intake influences this relationship. Non-pregnant women aged 18-40 years $(n 441)$ were recruited between February and June. Fasting blood was collected and dietary intakes were assessed using $5 \mathrm{~d}$ food records. Mean serum 25 -hydroxyvitamin D concentration was lower in Beijing than Hong Kong women $(29$ v. $34 \mathrm{nmol} / 1 ; P<0 \cdot 001)$. Vitamin D deficiency $(\leq 25 \mathrm{nmol} / \mathrm{l})$ was indicated in $40 \%$ of Beijing and $18 \%$ of Hong Kong women, and over $90 \%$ of women in both cities were insufficient $(\leq 50 \mathrm{nmol} / \mathrm{l})$. Mean Ca and vitamin D intakes were $478 \mathrm{mg} / \mathrm{d}$ and $2.0 \mu \mathrm{g} / \mathrm{d}$, respectively. The relationship between 25 -hydroxyvitamin D concentration and PTH was linear throughout the range with a slope of -0.36 (different from $0 ; P<0.001 ; R$ 0.26), with no apparent threshold. There was no influence of Ca intake on the relationship between 25-hydroxyvitamin D and PTH concentration. Vitamin D deficiency is common and insufficiency is very common in non-pregnant women in Hong Kong and Beijing during spring. Serum 25-hydroxyvitamin D was inversely associated with PTH with no apparent threshold. Strategies such as vitamin D fortification or supplementation may be required.
\end{abstract}

25-Hydroxyvitamin D: Parathyroid hormone: Calcium intake: Women: China

Vitamin D insufficiency has been associated with an increased risk of osteoporosis and other chronic diseases ${ }^{1-3}$. For women who become pregnant, vitamin D insufficiency also increases the risk of vitamin D deficiency in their infants ${ }^{4}$. Supplementation with vitamin D during pregnancy improves infant vitamin D status and may improve birth and infant health outcomes $^{5}$. The major source of vitamin D is UV light exposure and anything that influences the amount of light reaching the deeper epidermal layers of the skin, such as season, latitude, clothing, and darker skin colour, can influence vitamin D status ${ }^{1}$. Rickets has been reported to be common in China, particularly in the northern provinces during the winter months ${ }^{6}$. Further, high rates of vitamin D insufficiency, based on low circulating 25-hydroxyvitamin D concentrations, have been reported in adolescent girls ${ }^{7}$ and older adults ${ }^{8,9}$ living in China. Less is known about the vitamin D status of women of childbearing age. However, there is reason to suspect a high rate of vitamin D insufficiency in this population, even in women living in southern areas. Shift work and avoidance of skin tanning for cosmetic reasons may keep women indoors or covered up much of the day. Over $60 \%$ of women in a recent survey in Hong Kong ( $n$ 547) indicated that they did not like going in the $\operatorname{sun}^{10}$.

Vitamin D insufficiency increases blood parathyroid hormone (PTH) concentration. Chronically elevated PTH (secondary hyperparathyroidism) accelerates bone turnover and is thought to be the key mechanism of cortical bone loss related to vitamin D insufficiency ${ }^{11}$. PTH concentrations

Abbreviation: PTH, parathyroid hormone.

* Corresponding author: Dr Tim Green, fax +64 3479 7958, email tim.green@otago.ac.nz 
have been inversely associated with serum 25 -hydroxyvitamin D concentrations up until a threshold, above which PTH concentrations plateau at a minimum level. This threshold has been reported to be somewhere between 25 and $122 \mathrm{nmol} / \mathrm{l}^{12}$ and is often used as a criterion to define vitamin $\mathrm{D}$ adequacy. However, these studies have generally been of older Europeans ${ }^{12}$.

Here we describe the vitamin D status of women living in two Chinese cities during the spring: Beijing in the north (latitude $39^{\circ}$ north) and Hong Kong (latitude $22^{\circ}$ north) in the south. We also explore the relationship between 25 -hydroxyvitamin D and PTH concentrations in this population to determine if a threshold exists for serum 25-hydroxyvitamin D, above which PTH concentrations plateau. Finally, we examine whether dietary $\mathrm{Ca}$ intake modifies this relationship.

\section{Methods}

Subjects

We are presenting baseline data from participants in an intervention trial designed to investigate the effect of milk supplementation on bone mineral density among young non-pregnant women aged 20-35 years. Women were recruited, using flyers and mail-outs, from the cities of Beijing and Hong-Kong between February and May 2002. Women were excluded from the trial if they had breastfed within 12 months, had a serious or chronic illness, or were taking $\mathrm{Ca}$ or vitamin D supplements. Baseline measurements were available for 441 of the 501 eligible women who were screened: 221 in Hong Kong and 220 in Beijing. The remaining sixty did not attend their initial appointment. Approval to conduct the studies was provided from The Peking Union Medical College Hospital Ethics Committee, Beijing and The Chinese University of Hong Kong Ethics Committee, Hong Kong, China.

\section{Blood collection and laboratory analysis}

Blood samples were taken by venepuncture into evacuated tubes containing no anti-coagulant following an overnight fast, and allowed to clot for $30 \mathrm{~min}$. Serum was obtained by centrifuging the whole blood at $1650 \mathrm{~g}$ for $15 \mathrm{~min}$. Serum samples were stored at $-80^{\circ} \mathrm{C}$ until analysed. Serum 25-hydroxyvitamin D was determined using a RIA kit (Dia Sorin Inc., Stillwater, MN, USA), with an analytical sensitivity of $3.7 \mathrm{nmol} / 1$. A manufacturer-provided control, with an assigned range of $78-166 \mathrm{nmol} / \mathrm{l}$, was run with each kit. We obtained a mean value of $82 \mathrm{nmol} / \mathrm{l}$ for this control with an inter-assay CV of $9.1 \%$ ( $n$ 18). Serum PTH was measured by chemiluminescence immunoassay on an Immulite 1000 Analyzer (Diagnostic Products Corporation, Los Angeles, CA, USA), with an analytical sensitivity of $1 \mathrm{pg} / \mathrm{ml}$. We obtained a mean of $60 \mathrm{pg} / \mathrm{ml}$ and an inter-assay CV of $8.6 \%(n 23)$ for a manufacturer-provided control with an assigned mean of $65 \mathrm{pg} / \mathrm{ml}$. We defined vitamin $\mathrm{D}$ deficiency as 25-hydroxyvitamin D $\leq 25 \mathrm{nmol} / 1$ and vitamin D insufficiency as 25 -hydroxyvitamin $\mathrm{D} \leq 50 \mathrm{nmol} / \mathrm{l}^{13,14}$. We defined hyperparathyroidism as a serum PTH concentration greater than the upper limit of the reference range provided by the kit manufacturer $(>72 \mathrm{pg} / \mathrm{ml})$.

\section{Dietary data}

Dietary data were collected from each participant using a $5 \mathrm{~d}$ food record. The subjects were asked to fill out the food record before their clinic visit ${ }^{15}$. A nutritionist reviewed the completed $5 \mathrm{~d}$ food record with the participants. Different-sized utensils (i.e. bowls and spoons) as well as pictures of food items on a plate were used to help confirm the correct portion size. The food diaries were analysed by Food Processor version 8.0 (ESHA Research, Salem, OR, USA). Local and Chinese foods were added into the database based on manufacturer data and China Food Composition data of 2002 by the Institute of Nutrition and Food Safety of China ${ }^{16}$.

\section{Statistical analysis}

Differences between Hong Kong and Beijing were determined using a Fisher's exact test for categorical variables and a Student's $t$ test for continuous variables. Linear regression was used to examine the relationship between serum 25-hydroxyvitamin D and PTH. To determine if there was a threshold relationship between serum 25-hydroxyvitamin D and PTH we used the MKSPLINE function of STATA (Stata Corp., College Station, TX, USA). We moved the cut-off point for 25-hydroxyvitamin D concentration from $30-80 \mathrm{nmol} / 1$, in single-unit increments, and compared the slopes of the regression lines for data above and below the cut-off.

To examine the effect of $\mathrm{Ca}$ intake on the relationship between PTH and 25-hydroxyvitamin D, participants were divided into tertiles according to Ca intake (low, $<385 \mathrm{mg} / \mathrm{d}$; medium, $385-545 \mathrm{mg} / \mathrm{d}$; high, $>545 \mathrm{mg} / \mathrm{d}$ ), serum 25 -hydroxyvitamin D concentration (low, $<26 \mathrm{nmol} / \mathrm{l}$; medium, $26-35 \mathrm{nmol} / \mathrm{l}$; high, $>35 \mathrm{nmol} / \mathrm{l})$. We used multiple regression analysis with PTH as the dependent variable and Ca intake and serum 25-hydroxyvitamin D concentration as the independent variables, with and without an interaction term in the model.

\section{Results}

Women surveyed in Beijing were more likely to be married than women in Hong Kong (47 v. 29\%; $P<0.001$ ) (Table 1). The majority of women in both countries had received secondary education or higher. The overall mean serum 25-hydroxyvitamin D concentration of women in both cities was $32 \mathrm{nmol} / \mathrm{l}$. A total of $29 \%$ of women had a serum 25-hydroxyvitamin D concentration indicative of vitamin $\mathrm{D}$ deficiency $(<25 \mathrm{nmol} / \mathrm{l})$, whereas over $90 \%$ of women had a 25 -hydroxyvitamin D concentration indicative of insufficiency $(<50 \mathrm{nmol} / \mathrm{l})$. Women in Beijing had a lower mean 25-hydroxyvitamin D concentration (34 v. $29 \mathrm{nmol} / \mathrm{l} ; P<0.001)$ and higher rates of deficiency and insufficiency than women in Hong Kong. The mean PTH hormone concentration was $36 \mathrm{pg} / \mathrm{ml}$. Women in Beijing had higher mean PTH concentrations than women in Hong Kong (40 v. $34 \mathrm{pg} / \mathrm{ml} ; P<0.001)$. Overall, $13 \%$ of women had hyperparathyroidism $(>72 \mathrm{pg} / \mathrm{ml}$ ) with higher rates in Beijing than Hong Kong (24 v. $2 \% ; P<0.001)$. Mean dietary Ca intake was higher in Beijing than Hong Kong (506 v. $448 \mathrm{mg} / \mathrm{d}$; $P<0.001)$ but vitamin D intake was higher in Hong Kong (3.4 v. $0.9 \mu \mathrm{g} / \mathrm{d} ; P<0.001)$. The relationship between serum 25-hydroxyvitamin D concentration and PTH is depicted in 
Table 1. Participant characteristics, biochemical indices and dietary intakes

(Mean values and $95 \%$ confidence intervals)

\begin{tabular}{|c|c|c|c|c|c|c|}
\hline \multirow[b]{2}{*}{ Descriptive } & \multicolumn{2}{|c|}{ Overall } & \multicolumn{2}{|c|}{ Hong Kong } & \multicolumn{2}{|c|}{ Beijing } \\
\hline & Mean & $95 \% \mathrm{Cl}$ & Mean & $95 \% \mathrm{Cl}$ & Mean & $95 \% \mathrm{Cl}$ \\
\hline Number of women & \multirow{2}{*}{\multicolumn{2}{|c|}{441}} & \multirow{2}{*}{\multicolumn{2}{|c|}{221}} & \multirow{2}{*}{\multicolumn{2}{|c|}{220}} \\
\hline \multicolumn{3}{|l|}{ Age (years) } & & & & \\
\hline Mean & \multirow{2}{*}{\multicolumn{2}{|c|}{$\begin{array}{r}27.4 \\
0.2\end{array}$}} & \multicolumn{2}{|c|}{$27 \cdot 9$} & \multicolumn{2}{|c|}{$26 \cdot 9$} \\
\hline SD & & & \multicolumn{2}{|c|}{0.3} & \multicolumn{2}{|c|}{0.3} \\
\hline \multicolumn{5}{|l|}{ BMI $\left(\mathrm{kg} / \mathrm{m}^{2}\right)$} & & \\
\hline Mean & \multicolumn{2}{|c|}{$20 \cdot 8$} & \multicolumn{2}{|c|}{$20 \cdot 3$} & \multicolumn{2}{|c|}{$21 \cdot 3$} \\
\hline SD & \multicolumn{2}{|c|}{0.1} & \multicolumn{2}{|c|}{0.2} & \multicolumn{2}{|c|}{0.2} \\
\hline \multicolumn{7}{|l|}{ Ever been pregnant } \\
\hline$n$ & \multicolumn{2}{|c|}{183} & \multicolumn{2}{|c|}{89} & \multicolumn{2}{|c|}{94} \\
\hline$\%$ & \multicolumn{2}{|c|}{41} & \multicolumn{2}{|c|}{40} & \multicolumn{2}{|c|}{43} \\
\hline \multicolumn{7}{|l|}{ Smokers } \\
\hline$n$ & \multicolumn{2}{|c|}{12} & \multicolumn{2}{|c|}{9} & \multirow{2}{*}{\multicolumn{2}{|c|}{$\begin{array}{l}3 \\
1\end{array}$}} \\
\hline$\%$ & & & & & & \\
\hline Married & & & & & & \\
\hline$n$ & & & & & & \\
\hline$\%$ & & & & & & \\
\hline Post-secondary education & & & & & & \\
\hline$n$ & & & & & & \\
\hline$\%$ & & & & & & \\
\hline 25-Hydroxyvitamin D (nmol/l) & 32 & 30,33 & 34 & 33,36 & $29^{*}$ & 27,30 \\
\hline Women with 25 -hydroxyvitamin $\mathrm{D} \leq 25 \mathrm{nmol} / /(\%)$ & 29 & 25,33 & 18 & 13,23 & $40^{*}$ & 33,47 \\
\hline Women with 25 -hydroxyvitamin $\mathrm{D} \leq 50 \mathrm{nmol} / /(\%)$ & 93 & 90,95 & 92 & 88,95 & 94 & 91,97 \\
\hline PTH (pg/ml) & 36 & 35,38 & 34 & 32,35 & $40^{*}$ & 37,43 \\
\hline Women with PTH > $72 \mathrm{pg} / \mathrm{ml}(\%)$ & 13 & 8,16 & 2 & 0,4 & $24^{*}$ & 18,29 \\
\hline Ca intake $(\mathrm{mg} / \mathrm{d})$ & 478 & 461,495 & 448 & 426,471 & $506^{\star}$ & 481,532 \\
\hline Vitamin D intake $(\mu \mathrm{g} / \mathrm{d})$ & $2 \cdot 0$ & $1 \cdot 9,2 \cdot 4$ & 3.4 & $3 \cdot 0,3 \cdot 8$ & $0.9^{*}$ & $0.9,1.0$ \\
\hline
\end{tabular}

PTH, parathyroid hormone.

${ }^{*}$ Significantly different from Hong Kong women $(P<0.001)$.

Fig. 1. There was no threshold for serum 25-hydroxyvitamin D above which there was a plateau in PTH concentration. The relationship between 25 -hydroxyvitamin $\mathrm{D}$ concentration and PTH was linear throughout the range with a slope of -0.36 (different from $0 ; P<0.001$ ) and an $R$ for the model of $0 \cdot 26$. Fig. 2 gives the mean serum PTH for each tertile of serum 25-hydroxyvitamin $\mathrm{D}$ by tertile of dietary $\mathrm{Ca}$. In the regression model tertile of 25-hydroxyvitamin $\mathrm{D}(P<0.012)$ concentration but not tertile of Ca intake $(P=0.094)$ was associated with PTH concentration. There was no significant interaction between tertile of $\mathrm{Ca}$ intake and 25-hydroxyvitamin $\mathrm{D}$ concentration with serum PTH $(P=0.942)$. Additionally, tertile of Ca intake was not associated serum PTH $(P=0.158)$, independent of 25-hydroxyvitamin D concentration.

\section{Discussion}

Here we report a high rate of vitamin D deficiency (40\%) among young Beijing women during the spring months. Vitamin D deficiency was less common in Hong Kong women, but was still at $18 \%$. There is no consensus as to the most appropriate cut-off to define vitamin D insufficiency; however, some experts contend that levels for optimal health and chronic disease reduction are $100 \mathrm{nmol} / \mathrm{l}$ or higher ${ }^{17}$. Nevertheless, even using a conservative cut-off of $50 \mathrm{nmol} / 1$, more than $90 \%$ of women in both cities were vitamin D insufficient. Vitamin D insufficiency may increase the risk of osteoporotic fracture later in life $^{18}$ and has been associated with an increased risk of a number of non-skeletal outcomes such as falls, diabetes and rheumatoid arthritis, poor dental health and certain types of cancer ${ }^{1}$. For women who become pregnant, adequate vitamin D status is important ${ }^{4}$. Maternal and cord blood 25-hydroxyvitamin D concentrations are correlated and maternal supplementation improves infant vitamin D status. Vitamin D insufficiency has been reported in several Asian countries in diverse study populations ${ }^{19,20}$. However, there is scant data on the vitamin D status of Chinese women of childbearing age to compare our findings with. Nevertheless, the mean 25-hydroxyvitamin D concentrations we report in Beijing (latitude $39^{\circ}$ north) are somewhat lower than those reported in a small study conducted in Shenyang (latitude $41^{\circ}$ north), a city north-east of Beijing, in which women (25-35 years; $n$ 38) had a mean serum 25-hydroxyvitamin D concentration of 40.7 (SD 14.1) nmol/l, assessed in early spring ${ }^{8}$. The mean vitamin D concentrations reported in our group were much higher than those reported in urban Beijing adolescent girls (age 12-44 years; $n$ 108) in either winter or summer of 13.9 (SD 9.6) and 30.2 (SD 11.9 ) nmol/l, respectively ${ }^{7}$. The high rate of insufficiency in Hong Kong was unexpected given its sub-tropical climate and mild winters. Indeed a higher mean 25-hydroxyvitamin D concentration of $70 \mathrm{nmol} / \mathrm{l}$ was reported in older Hong Kong residents aged $>50$ years $(n 382)$, and although $61 \%$ of these samples were taken in summer there was no significant difference in vitamin $\mathrm{D}$ concentration between those collected in summer or winter ${ }^{9}$. We recently reported that Chinese (age $18-40$ years; $n$ 123) women living in Kuala Lumpur (latitude $2^{\circ}$ north) had a mean 25-hydroxyvitamin D concentration of $123 \mathrm{nmol} / \mathrm{l}$. Not surprisingly, this is 


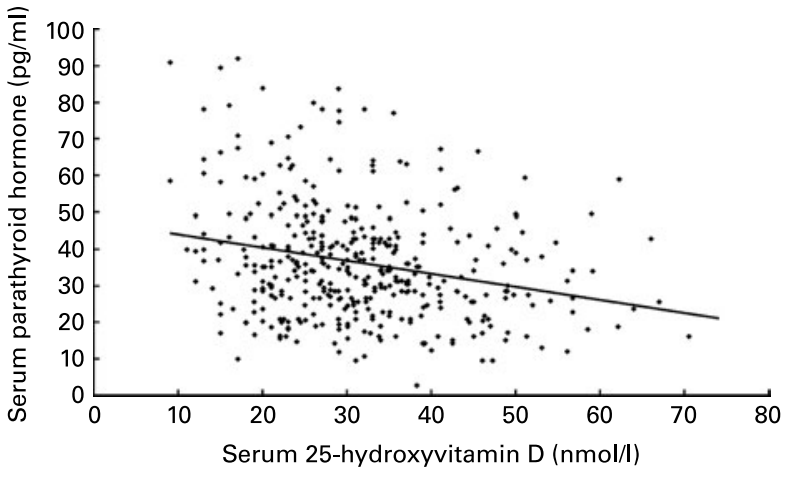

Fig. 1. Association of serum parathyroid hormone with 25-hydroxyvitamin D concentration ( $n$ 441). The slope of the fitted regression line is depicted $(y=-0.36 x+47 \cdot 6 ; R-0.26)$.

somewhat higher than we report in Beijing or Hong Kong; although, even in Kuala Lumpur vitamin D insufficiency was not uncommon at $38 \%{ }^{21}$.

We were unable to assess the reasons for low 25-hydroxyvitamin $\mathrm{D}$ concentrations in the young Chinese women in our study. There are, however, a number of possible explanations. Beijing lies at latitude $39^{\circ}$ north with an average January temperature of $-4 \cdot 2{ }^{\circ} \mathrm{C}$ that will limit the time that women spend outdoors and decrease UV exposure. In Hong Kong the reasons for low vitamin D are less obvious but factors such as sun avoidance for cosmetic reasons, shift work and an indoor lifestyle may be part of the explanation. Pollution and cloud cover are other possibilities. Finally, mean vitamin D intakes in both cities were well below the current US Institute of Medicine adequate intake of $5 \mu \mathrm{g} / \mathrm{d}$, a recommended intake that may be too low to acheive a 25 -hydroxyvitamin D concentration above $50 \mathrm{nmol} / \mathrm{l}^{22}$.

Hyperparathyroidism, presumably secondary due to a lack of vitamin $\mathrm{D}$, was present in only $2 \%$ of Hong Kong but nearly $25 \%$ of Beijing women. Secondary hyperparathyroidism leads to bone loss and, if prolonged, leads to increased risk of osteoporotic fracture ${ }^{11}$. Serum 25-hydroxyvitamin D was inversely associated with PTH throughout the range of vitamin D concentration, with no apparent threshold. Since most estimates of a vitamin D-replete state based on PTH minimisation are greater than $50 \mathrm{nmol} / \mathrm{l}$, a possible reason for our inability to detect a

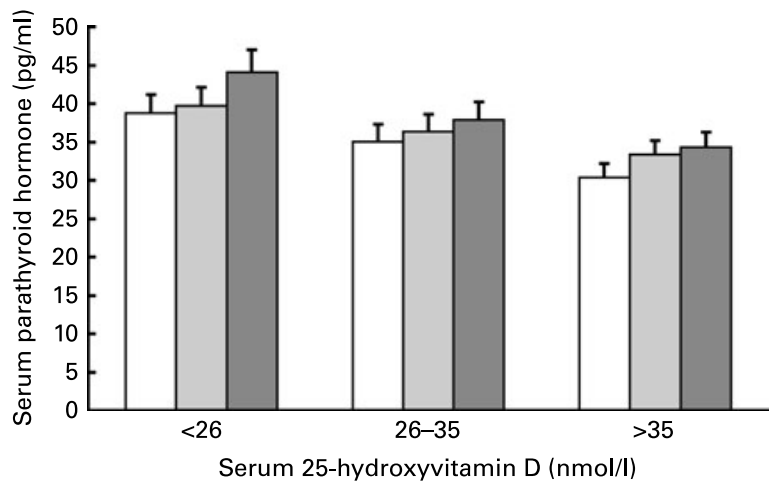

Fig. 2. Serum parathyroid hormone concentration by tertile of serum 25-hydroxyvitamin D concentration and tertile of Ca intake: $(\square),<385 \mathrm{mg} / \mathrm{d}$; ( $\square$ ), $385-545 \mathrm{mg} / \mathrm{d}$; $(\square)>545 \mathrm{mg} / \mathrm{d}$. Values are means, with their $95 \% \mathrm{Cl}$ represented by vertical bars. threshold was a lack of high serum 25-hydroxyvitamin D concentrations $^{12}$. Less than $7 \%$ of women had 25 -hydroxyvitamin D concentrations greater than $50 \mathrm{nmol} / \mathrm{l}$ and no women had a concentration greater than $75 \mathrm{nmol} / 1$. There are no other similar data for young Chinese women. However, we recently estimated this threshold at $52 \mathrm{nmol} / \mathrm{l}$ in a survey of young women living in Kuala Lumpur and Jakarta ${ }^{21}$. The vitamin D requirements for optimal pregnancy outcome or non-skeletal outcomes may be higher than that required to suppress PTH. Further, the relationship between vitamin $\mathrm{D}, \mathrm{PTH}$, and bone health may not be consistent across all ethnicities. African-Americans have lower 25-hydroxyvitamin D and higher PTH than white Americans but have better bone mineral density, suggesting that they may be resistant to the action of $\mathrm{PTH}^{12}$. A similar finding was recently reported in older Chinese compared with Britons ${ }^{23}$.

Steingrimsdottir et al. ${ }^{24}$ reported in an Icelandic adult population that the increase in PTH, when 25-hydroxyvitamin D was less than $25 \mathrm{nmol} / \mathrm{l}$, was more pronounced in those in the lowest tertile of $\mathrm{Ca}$ intake $(<800 \mathrm{mg} / \mathrm{d})$. In the present study, PTH concentrations decreased across the categories (low, medium, high) of serum 25-hydroxyvitamin D but, within each category of vitamin D status, Ca intake had no effect on PTH concentrations. Since less than $10 \%$ of our participants had Ca intakes greater than $800 \mathrm{mg} / \mathrm{d}$, it is likely that in the present study $\mathrm{Ca}$ intakes were not high enough to suppress PTH.

We acknowledge a number of limitations of the present study. Participants were surveyed in spring only and it is likely that we measured vitamin D concentrations when they were at their lowest. A seasonal variation in 25-hydroxyvitamin D concentrations is well described, with lower concentrations in late winter and early spring. As this effect is more pronounced at higher latitudes the seasonal difference in 25-hydroxyvitamin D concentrations would be expected to be greater in Beijing than Hong Kong. Also, as our sample was non-random we cannot generalise our findings to all women of childbearing age living in these cities. Many women in the present study had attended university or polytechnic and, thus, were likely to be of higher socio-economic status than the general population.

In conclusion, vitamin D deficiency is common and insufficiency is very common in non-pregnant women in Hong Kong and Beijing during spring. Serum 25-hydroxyvitamin D was inversely associated with PTH with no apparent threshold. Low vitamin D status coupled with low Ca intakes in these women may increase their risk of osteoporotic fracture and other negative outcomes later in life. Strategies such as food fortification or supplementation are required to improve the vitamin D status of women in these cities.

\section{Acknowledgements}

The present study was supported by a research grant from Fonterra Brands Limited, Auckland, New Zealand.

J. W., T. J. G., C. M. S. and S. J. W. conceived the idea for the cross-sectional study of vitamin D status of Chinese women. J. W., C. W. K. L., J. L., W. L., X. L., X. X., X. H. Z. and A. L. conceived and conducted the larger intervention trial designed to investigate the effect of milk supplementation on bone mineral density. All authors contributed to writing the manuscript. 
A. L. is an employee of Fonterra Brands Limited, Auckland, New Zealand, a company that markets dairy products in Asia. None of the other authors reports a personal or financial interest.

\section{References}

1. Holick MF (2004) Sunlight and vitamin D for bone health and prevention of autoimmune diseases, cancers, and cardiovascular disease. Am J Clin Nutr 80, 1678S-1688S.

2. Chapuy MC, Pamphile R, Paris E, Kempf C, Schlichting M, Arnaud S, Garnero P \& Meunier PJ (2002) Combined calcium and vitamin D3 supplementation in elderly women: confirmation of reversal of secondary hyperparathyroidism and hip fracture risk: the Decalyos II study. Osteoporos Int 13, 257-264.

3. Dawson-Hughes B, Harris SS, Krall EA \& Dallal GE (1997) Effect of calcium and vitamin D supplementation on bone density in men and women 65 years of age or older. $N$ Engl J Med 337, 670-676.

4. Hollis BW \& Wagner CL (2004) Assessment of dietary vitamin D requirements during pregnancy and lactation. Am J Clin Nutr 79, 717-726.

5. Brooke OG, Brown IR, Bone CD, Carter ND, Cleeve HJ, Maxwell JD, Robinson VP \& Winder SM (1980) Vitamin D supplements in pregnant Asian women: effects on calcium status and fetal growth. BMJ 280, 751-754.

6. Strand MA, Perry J, Jin M, Tracer DP, Fischer PR, Zhang P, Xi W $\& \mathrm{Li} \mathrm{S}$ (2007) Diagnosis of rickets and reassessment of prevalence among rural children in northern China. Pediatr Int 49, 202-209.

7. Du X, Greenfield H, Fraser DR, Ge K, Trube A \& Wang Y (2001) Vitamin D deficiency and associated factors in adolescent girls in Beijing. Am J Clin Nutr 74, 494-500.

8. Yan L, Prentice A, Zhang H, Wang X, Stirling DM \& Golden MM (2000) Vitamin D status and parathyroid hormone concentrations in Chinese women and men from north-east of the People's Republic of China. Eur J Clin Nutr 54, 68-72.

9. Wat WZ, Leung JY, Tam S \& Kung AW (2007) Prevalence and impact of vitamin D insufficiency in southern Chinese adults. Ann Nutr Metab 51, 59-64.

10. Kung AW \& Lee KK (2006) Knowledge of vitamin D and perceptions and attitudes toward sunlight among Chinese middleaged and elderly women: a population survey in Hong Kong. BMC Public Health 6, 226.
11. Lips $\mathbf{P}$ (2001) Vitamin D deficiency and secondary hyperparathyroidism in the elderly: consequences for bone loss and fractures and therapeutic implications. Endocr Rev 22, 477-501.

12. Aloia JF, Talwar SA, Pollack S, Feuerman M \& Yeh JK (2006) Optimal vitamin D status and serum parathyroid hormone concentrations in African American women. Am J Clin Nutr 84, 602-609.

13. Dawson-Hughes B, Heaney RP, Holick MF, Lips P, Meunier PJ \& Vieth R (2005) Estimates of optimal vitamin D status. Osteoporos Int 16, 713-716.

14. McKenna MJ \& Freaney R (1998) Secondary hyperparathyroidism in the elderly: means to defining hypovitaminosis D. Osteoporos Int 8, Suppl. 2, S3-S6.

15. Gibson RS (2005) Principles of Nutritional Assessment. Auckland: Oxford University Press.

16. Yang Y, Wang G \& Pan X (2002) China Food Composition. Beijing: Peking University Medical Press.

17. Bischoff-Ferrari HA, Giovannucci E, Willett WC, Dietrich T \& Dawson-Hughes B (2006) Estimation of optimal serum concentrations of 25-hydroxyvitamin D for multiple health outcomes. Am J Clin Nutr 84, 18-28.

18. Heaney RP (2003) Long-latency deficiency disease: insights from calcium and vitamin D. Am J Clin Nutr 78, 912-919.

19. Fraser DR (2004) Vitamin D-deficiency in Asia. J Steroid Biochem Mol Biol 89-90, 491-495.

20. Lips P (2007) Vitamin D status and nutrition in Europe and Asia. J Steroid Biochem Mol Biol 103, 620-625.

21. Green TJ, Skeaff CM, Rockell JE, et al. (2007) Vitamin D status and its association with parathyroid hormone concentrations in women of child-bearing age living in Jakarta and Kuala Lumpur. Eur J Clin Nutr (Epublication ahead of print version 7 March 2007).

22. Vieth R, Bischoff-Ferrari H, Boucher BJ, et al. (2007) The urgent need to recommend an intake of vitamin $\mathrm{D}$ that is effective. Am J Clin Nutr 85, 649-650.

23. Yan L, Zhou B, Wang X, D'Ath S, Laidlaw A, Laskey MA \& Prentice A (2003) Older people in China and the United Kingdom differ in the relationships among parathyroid hormone, vitamin D, and bone mineral status. Bone 33, 620-627.

24. Steingrimsdottir L, Gunnarsson O, Indridason OS, Franzson L \& Sigurdsson G (2005) Relationship between serum parathyroid hormone levels, vitamin D sufficiency, and calcium intake. JAMA 294, 2336-2341. 